\title{
Nonrecurrent Laryngeal Nerve: A Case Report and a Review of an Important Anatomical Variant
}

\author{
Prashant Sukharamwala, Seth Korbin, Abdul Ghani, James Smith
}

\begin{abstract}
An important anatomical structure commonly encountered during major head and neck surgery is the recurrent inferior laryngeal nerve. Nonrecurrent inferior laryngeal nerve variants are rarely encountered. Although much less common, these variants represent a significant risk for intraoperative nerve injury and patient morbidity. We present a case of a right nonrecurrent inferior laryngeal nerve variant along with a retrospective analysis and systematic review investigating the overall incidence of these variants.
\end{abstract}

Keywords: Nonrecurrent inferior laryngeal nerve, Vocal cord paralysis, Parathyroidectomy, Thyroidectomy.

How to cite this article: Sukharamwala P, Korbin S, Ghani A, Smith J. Nonrecurrent Laryngeal Nerve: A Case Report and a Review of an Important Anatomical Variant. World J Endoc Surg 2012;4(3):112-114.

\section{Source of support: Nil}

Conflict of interest: None

\section{INTRODUCTION}

Identification of a recurrent inferior laryngeal nerve is of great concern to the surgeon performing procedures involving the thyroid gland and/or the parathyroid glands because of the major morbidity associated with its injury. Unilateral injury to the recurrent inferior laryngeal nerve can lead to hoarseness of voice, while bilateral involvement can potentially produce emergent airway obstruction. Although occurring less frequently, the presence of a nonrecurrent inferior laryngeal nerve must also be identified. Surgeons must be aware of the normal anatomical variations and should maintain a low threshold of suspicion when operating in this area due to a significant morbidity.

A nonrecurrent right laryngeal nerve can arise directly from the vagus nerve and course medially into the larynx. It is most commonly associated with an aberrant right subclavian artery. ${ }^{1}$ Occasionally, a recurrent laryngeal nerve and nonrecurrent inferior laryngeal nerve are both present and join to form a common distal nerve (Figs 1A to C). Nonrecurrent left laryngeal nerves are extremely rare and are associated with aortic arch anomalies, such as situs inversus viscerum. ${ }^{2}$

\section{METHODS}

A retrospective study of 635 patients who underwent thyroid and parathyroid surgery at Northside Medical Center was performed during the period between January 1991 and March 2012. Permission was obtained from the Institutional Review Board to perform this study. Clinical data was obtained from a review of operative records. Two hundred and forty-three (243) patients underwent thyroid surgery and 392 patients underwent parathyroid surgery. One case of nonrecurrent right inferior laryngeal nerves $(0.16 \%)$ was noted.

An electronic literature search was also performed for all articles from January 1980 to March 2012 (Table 1). Medline, the Cochrane Library, SCI, EMBASE were all searched using the following text and keywords both as MeSH terms and text words: 'Thyroidectomy', 'parathyroidectomy' and 'nonrecurrent inferior laryngeal nerve'. Further searches were extended to otolaryngology journals. In addition, references of included studies were screened for any additional literature. Only studies that contained institute incidence were included. As noted by previous studies, and the one conducted by our institution, nonrecurrent laryngeal nerves occur with a very low incidence (less than 1\%), with right-sided occurring more commonly than the left (Table 1). ${ }^{3-11}$

\section{CASE REPORT}

We report a 48-year-old female who was referred for primary hyperparathyroidism. A 99Tc Sestamibi scan demonstrated a persistent area of focal uptake in the right lobe compatible
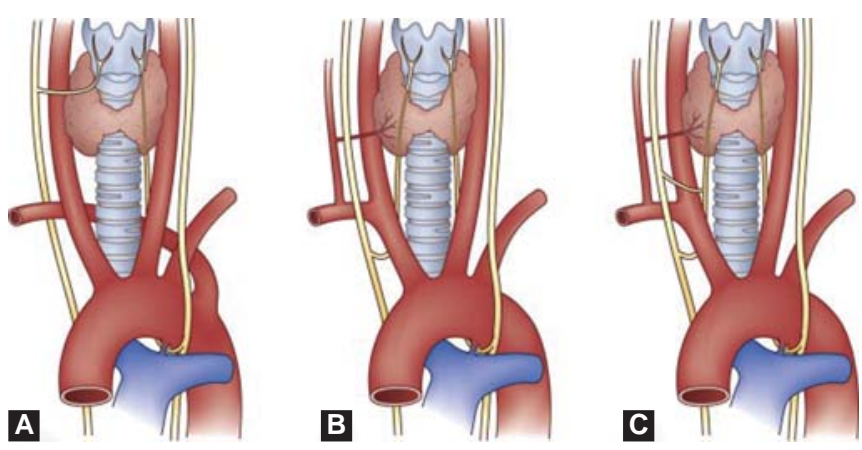

Figs 1A to $\mathrm{C}$ : Anomalous variations in the course of the right recurrent laryngeal nerve. (A) The nonrecurrent laryngeal nerve arises from the vagus and courses medially into the larynx in the setting of an aberrant origin of the right subclavian artery. (B) The normal course of the recurrent laryngeal nerve arises from the vagus after it passes beneath the subclavian artery. (C) The unusual coexistence of the nonrecurrent and the recurrent laryngeal nerve join to form a common distal nerve [Adapted with permission Sabiston Textbook of Surgery: The Biological Basis of Modern Surgical Practice (19th ed). Philadelphia, PA: Elsevier 2012, p.886] 
with a right-sided parathyroid adenoma. The patient was scheduled to undergo a focused parathyroidectomy.

A right inferior parathyroidectomy was performed in which the strap muscles were retracted laterally and the right lobe of the thyroid was mobilized and rotated medially. The nonrecurrent inferior laryngeal nerve was immediately identified taking a transverse course from the vagus nerve toward the posterior aspect of the right thyroid lobe in the direction of the larynx (Fig. 2). No additional recurrent laryngeal nerve on the right side was identified in the tracheoesoghageal groove. The parathyroid adenoma was removed and the postoperative course was uneventful. No voice hoarseness was noted by the patient. Review of the pathological specimen demonstrated the presence of hypercellular parathyroid gland consistent with parathyroid adenoma with no malignant cells.

\section{DISCUSSION}

Identification of the inferior laryngeal nerve is an important aspect in head and neck surgery, especially those procedures that involve the thyroid and parathyroid (and carotid endarterectomy). In the United States, 70\% of medicolegal claims involving surgical procedures of the thyroid and parathyroid are related to recurrent inferior laryngeal nerve injury. ${ }^{12}$ Ipsilateral vocal cord paralysis and voice hoarseness is directly related to nerve injury. Bilateral injury is associated with global vocal cord paralysis leading to severe airway obstruction.

In 1823, Stedman described the presence of nonrecurrent inferior laryngeal nerve in a cadaver study. ${ }^{13}$ In 1932, the surgical risk of this anomaly was reported to be associated with a lusorial artery (aberrant right subclavian artery) arising from the descending aorta. ${ }^{14}$ Since, anomalous subclavian arteries are associated with the nonrecurrent inferior laryngeal nerves, some authors have recommended ultrasound duplex scanning in selected patients as a simple, noninvasive method of identifying patients suspected to have arterial abnormalities responsible for a nonrecurrent inferior laryngeal nerve. ${ }^{15,16}$

Although the incidence of the nonrecurrent inferior laryngeal nerves is relatively low, it is important to be knowledgeable about the possible anatomical variants (Fig. 1). Poor understanding of the anatomy and less than meticulous dissection can lead to serious patient morbidity. ${ }^{16}$ In addition to anatomical knowledge and awareness of this variant during dissection, intraoperative nerve monitoring of the recurrent inferior laryngeal nerve is an option recommended as a risk reduction tool. ${ }^{16}$ The best way to avoid nerve injury is do a meticulous systematic dissection based on usual anatomic landmarks (i.e. tracheoesoghageal groove, berry ligament, middle thyroid vein and inferior thyroid artery). When the recurrent inferior laryngeal nerve is not found in its usual position, one should suspect a nonrecurrent inferior laryngeal nerve. Except for the middle thyroid vein, any transverse bands between the carotid artery and the larynx should be carefully examined before its transection, including use of intraoperative nerve monitoring. ${ }^{16}$ Appreciation of the anatomic variations and systematic dissection is key in avoiding an accidental injury to the nonrecurrent inferior laryngeal nerve.

\section{CONCLUSION}

Although the nonrecurrent inferior laryngeal nerve is very rarely located on the right and exceptional on the left, it

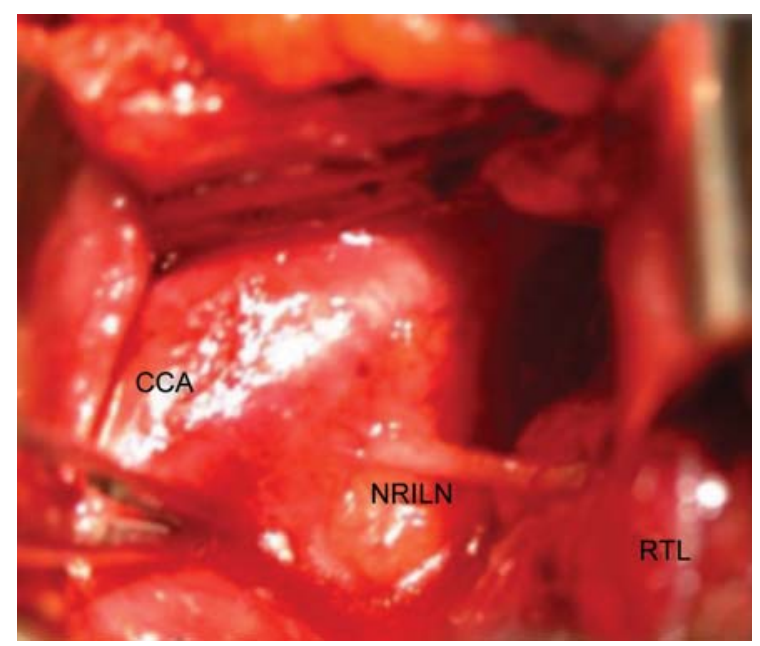

Fig. 2: Right nonrecurrent inferior laryngeal nerves with its transverse course from the vagus to the larynx (CCA: Common carotid artery, NRILN: Nonrecurrent inferior laryngeal nerve, RTL: Right thyroid lobe)

\begin{tabular}{|c|c|c|c|}
\hline Study & Total head and neck surgeries & Number of nonrecurrent laryngeal nerves & Incidence (\%) \\
\hline Li et $\left.a\right|^{3}$ & 2496 & 5 & 0.61 \\
\hline Docimo et $\mathrm{al}^{4}$ & 301 & 1 & 0.33 \\
\hline Page et $\mathrm{al}^{5}$ & 1557 & 3 & 0.19 \\
\hline Sciume et $\mathrm{al}^{6}$ & 514 & 2 & 0.39 \\
\hline Marone et $\mathrm{al}^{7}$ & 992 & 2 & 0.2 \\
\hline Dvorak et $\mathrm{al}^{8}$ & 1200 & 3 & 0.25 \\
\hline Sparta et $\mathrm{al}^{9}$ & 299 & 2 & 0.72 \\
\hline Defechereux et $\mathrm{al}^{10}$ & 2517 & 20 & 0.79 \\
\hline Henry et $\mathrm{al}^{11}$ & 6307 & 33 & 0.52 \\
\hline
\end{tabular}


still poses a major surgical risk. Not all the nonrecurrent inferior laryngeal nerves are associated with vascular anomaly. Thorough anatomic knowledge and meticulous dissection are essential for identifying any normal variants of the recurrent inferior laryngeal nerve and to avoid its injury.

\section{REFERENCES}

1. Huang SM, Wu TJ. Neck ultrasound for prediction of right nonrecurrent laryngeal nerve. Head Neck 2010;32:844-49.

2. Townsend CM, Beauchamp DR, Evers MB, Mattox KL. Sabiston textbook of surgery: The biological basis of modern surgical practice (19th ed). Philadelphia, PA: Elsevier 2012;886.

3. Li X, Wang Z, Lu X, Li J, et al. Nonrecurrent laryngeal nerve related to thyroid surgery: A report of 5 cases and literature review. Med Sci Monit 2010 Jun;16(6):CS71-75.

4. Docimo G, Avenia N, Ragusa M, et al. Non recurrent inferior laryngeal nerve: Our surgical experience (In Italian with English Abstract) Clin Ter 2009;160(5):347-49.

5. Page C, Monet P, Peltier J, Bonnaire B, Strunski V. Nonrecurrent laryngeal nerve related to thyroid surgery: Report of three cases. J Laryngol Otol 2008 Jul;122(7):757-61.

6. Sciumè $\mathrm{C}$, Geraci $\mathrm{G}$, Pisello $\mathrm{F}$, et al. Nonrecurrent laryngeal nerve. Personal experience (In Italian with English Abstract). G Chir 2005 Nov-Dec;26(11-12):434-37.

7. Marone U, Pezzullo L, Chiofalo MG, Caracò C, Mozzillo N. The right inferior laryngeal nerve with a nonrecurrent course (In Italian with English Abstract). Tumori 2003 Jul-Aug; 89(Suppl 4):212-14.

8. Dvorák J, Kubín S, Hofmann J, Dyrc D. Nonrecurrent laryngeal nerve (In Czech with English Abstract). Rozhl Chir 2004 Feb; 83(2):62-66.

9. Spartà C, Cossu ML, Fais E, et al. Nonrecurrent inferior laryngeal nerve: Anatomy, frequency, and surgical considerations (In Italian with English Abstract). Minerva Chir 2004 Dec; 59(6):555-61.

10. Defechereux T, Albert V, Alexandre J, Bonnet P, Hamoir E, Meurisse $\mathrm{M}$. The inferior nonrecurrent laryngeal nerve: A major surgical risk during thyroidectomy. Acta Chir Belg 2000 MarApr;100(2):62-67.
11. Henry JF, Audiffret J, Denizot A, Plan M. The nonrecurrent inferior laryngeal nerve: Review of 33 cases, including two on the left side. Surgery 1988 Dec;104(6):977-84.

12. Kern KA. An overview of 711 general surgery liability cases. The anatomy of surgical malpractice claims. Bull Am Coll Surg 1995 Aug;80(8):34-49.

13. Stedman GW. A singular description of some of the nerves and the arteries of the neck and the top of the thorax. Edin Med Surg J 1823;19:564-65.

14. Pemberton J, Beaver MG. Anomaly of the right recurrent laryngeal nerve. Surg Gynecol Obstet 1932;54:594-95.

15. Devèze A, Sebag F, Hubbard J, Jaunay M, Maweja S, Henry JF. Identification of patients with a nonrecurrent inferior laryngeal nerve by duplex ultrasound of the brachiocephalic artery. Surg Radiol Anat 2003 Jul-Aug;25(3-4):263-69.

16. Dralle H, Sekulla C, Lorenz K, Brauckoff M, Machens A. German IONM Study Group: Intraoperative monitoring of the recurrent laryngeal nerve in thyroid surgery. World J Surg 2008 Jul;32(7):1358-66.

\section{ABOUT THE AUTHORS}

\section{Prashant Sukharamwala (Corresponding Author)}

Chief Resident, Department of General Surgery, Northside Medical Center, Youngstown, Ohio, USA, e-mail: prashantsukharamwala@yahoo.com

\section{Seth Korbin}

Medical Student, Department of Surgery, Northside Medical Center Youngstown, Ohio, USA

\section{Abdul Ghani}

Professor, Department of General Surgery, Northside Medical Center Youngstown, Ohio, USA

\section{James Smith}

Associate Professor and Chairman, Department of Surgery, Northside Medical Center, Youngstown, Ohio, USA 